\title{
Stress in parents of children born very preterm is predicted by child externalising behaviour and parent coping at age 7 years
}

\author{
Mark A Linden, ${ }^{1}$ Ivan L Cepeda, ${ }^{2}$ Anne Synnes, ${ }^{2,3}$ Ruth E Grunau ${ }^{1,2,3}$
}

${ }^{1}$ School of Nursing and Midwifery, Queen's University Belfast, Belfast, UK ${ }^{2}$ Department of Developmental Neurosciences \& Child Health, Child \& Family Research Institute, Vancouver, British Columbia, Canada

${ }^{3}$ Department of Pediatrics, University of British Columbia, Vancouver, British Columbia, Canada

\section{Correspondence to} Dr Mark A Linden, School of Nursing and Midwifery, Queen's University Belfast, 97 Lisburn Road, Belfast BT9 7BL, UK; M.Linden@qub.ac.uk

Received 19 August 2014 Accepted 19 February 2015 Published Online First 11 March 2015
CrossMark

To cite: Linden $M A$, Cepeda IL, Synnes A, et al. Arch Dis Child

2015;100:554-558.

\section{ABSTRACT}

Objective To examine factors which predict parenting stress in a longitudinal cohort of children born very preterm, and seen at age 7 years.

Methods We recruited 100 very preterm ( $\leq 32$ weeks gestational age) child-parent dyads and a control group of 50 term-born dyads born between 2001 and 2004 with follow-up at 7 years. Parents completed the Parenting Stress Index, Ways of Coping Questionnaire, Child Behavior Check List, Beck Depression Inventory and the State Trait Anxiety Inventory questionnaires. Child IQ was assessed using the Wechsler Intelligence Scale-IV.

Results After controlling for maternal education, parents of preterm children $(95 \% \mathrm{Cl} 111.1$ to 121.4$)$ scored higher $(p=0.027)$ on the Parenting Stress Index than term-born controls ( $95 \% \mathrm{Cl} 97.8$ to 113.2 ). Regression analyses showed that child externalising behaviour, sex and parent escape/avoidance coping style, predicted higher parenting stress in the preterm group. Parents of preterm girls expressed higher levels of stress than those of boys.

Conclusions Maladaptive coping strategies contribute to greater stress in parents of very preterm children. Our findings suggest that these parents need support for many years after birth of a very preterm infant.

\section{INTRODUCTION}

The majority of studies examining mental health in parents of children born very preterm ( $\leq 32$ weeks GA) have been conducted close to discharge from the neonatal intensive care unit (NICU) ${ }^{1} 2$ or early in childhood. ${ }^{3}$ In early childhood, mothers of highrisk very preterm infants self-report greater levels of stress at 8 months, 18 months ${ }^{3}$ and at 3 years, ${ }^{4}$ compared with mothers of term-born children. Few studies ${ }^{5}$ have examined parenting stress long-term in this population beyond the first few years of life. Understanding the factors which affect parenting stress is important due to the relationship between family function and child neurodevelopment and behaviour. ${ }^{6-8}$ High levels of maternal stress have been associated with both child internalising and externalising behaviours, ${ }^{9-11}$ reduced interactive play between mother and child, ${ }^{12}$ and higher levels of controlling behaviour. ${ }^{13}$

The additional stress of caring for a very preterm infant with medical complications has been shown to result in mothers employing coping strategies, such as denial and mental disengagement. ${ }^{14}$ The sex of the child has also been shown to affect parental stress with parents of preterm girls at

\section{What is already known on this topic?}

Parents of preterm children experience significantly higher levels of stress than their term-born counterparts following discharge from the neonatal intensive care unit.

- High levels of maternal stress are related to problem behaviours in preterm children.

- Poorer family functioning is related to parent stress.

\section{What this study adds?}

- This is the first study to show that coping in parents of very preterm children is related to parenting stress at 7 years.

- Children's externalising behaviour and sex were predictive of stress in parents of very preterm children, but not child IQ.

- Differences in stress between parents of preterm and term children still exist 7 years after birth.

8 months expressing higher levels of stress than those of preterm boys or full-term boys and girls. ${ }^{3}$ Parenting stress remains higher in parents of preterm children at early school age. ${ }^{5}$ Moreover, very preterm birth has been associated with reduced family functioning in regard to problem solving, communication and affective response, in addition to increased levels of parental stress, anxiety and depression at the age of 7 years. ${ }^{5}$ However, it appears that with time, mothers of young adults (aged 22-25 years) who were born extremely preterm, reported no differences in mood, state anxiety, social support or depression when compared with mothers of term-born controls. $^{15}$

Due to the relative lack of research on long-term parenting stress following birth of a preterm infant, the aim of the current study was to explore the effects of preterm birth on parenting stress in a prospective longitudinal cohort of children born very preterm, compared with full-term controls, when the children were at the age of 7 years. Factors related to parent education and coping style, as well as child cognition and behaviour were considered. 


\section{METHODS}

\section{Participants}

Children were seen at age 7 years as part of a longitudinal follow-up study of pain and neurodevelopment in children born very preterm. ${ }^{16}{ }^{17}$ Full-term children were recruited for comparison purposes for neurodevelopmental outcomes. Therefore, for the main goals of this longitudinal cohort project, the study design required over sampling of preterm infants to examine multiple clinical and social predictors from birth to school age. One hundred and six children born very preterm ( $\leq 32$ weeks GA) admitted to the level III NICU, with no major congenital anomalies, at British Columbia's Women's Hospital and Health Centre, Vancouver, Canada, between February 2001 and July 2004 were included in this study. Fifty children born full-term during the same period in the Vancouver region, recruited at birth through their paediatricians, comprised the control group. Preterm children were excluded from this study if they had a diagnosis of autism $(n=1)$ or severe brain injury and/or major sensory (blind, deaf), motor (non-ambulatory cerebral palsy) or cognitive (IQ $<70)$ impairment $(n=5)$. The final sample of preterm children included 50 males and 50 females comprising 27 twins, 5 triplets and 68 single births. Full-term controls (20 males and 30 females) were all born healthy and none had a pre-existing medical condition. There were two twin births and 48 single births in the full-term group. The parent who was the primary caregiver (85 preterm, 49 full-term) also participated in this study. Maternal education was chosen as a measure of socioeconomic status as recommended by previous research. ${ }^{18} 19$ Child and parent characteristics are presented in table 1 .

Ethical approval was granted for the study by the University of British Columbia/British Columbia's Women's Hospital and Health Centre Research Ethics Board. All parents provided written informed consent with children giving verbal assent.

\section{Measures}

Parents completed the following questionnaires.

Parenting Stress Index (PSI third edition), ${ }^{20}$ a standardised self-report tool consisting of 120 items, comprised of Child and Parent domains. Only the Parent domain was used in the present study, and comprises seven subscales (Competence, Isolation, Attachment, Health, Role Restriction, Depression, and Spouse/Parenting Partner Relationship) that measure stress related to characteristics of the parent. Parents are asked to respond on a 6-point Likert scale where $1=$ strongly agree and $6=$ strongly disagree. Higher scores on the PSI indicate greater levels of stress.

Ways of Coping Questionnaire (WCQ), ${ }^{21}$ a 66 -item selfreport tool, is divided into eight coping scales (Confrontive Coping, Distancing, Self-Controlling, Seeking Social Support, Accepting Responsibility, Escape-Avoidance, Planful Problem Solving, and Positive Reappraisal). Parents are asked to consider the extent to which they have used each strategy in response to

Table 1 Characteristics of study participants

\begin{tabular}{|c|c|c|c|c|}
\hline & \multicolumn{2}{|l|}{ Group } & \multirow[b]{2}{*}{$\mathrm{p}$ Value } & \multirow[b]{2}{*}{$95 \% \mathrm{Cl}$} \\
\hline & Preterm $(n=100)$ & Full-term $(n=50)$ & & \\
\hline \multicolumn{5}{|l|}{ Neonatal characteristics } \\
\hline Gender (male) n (\%) & $50(50)$ & $20(40)$ & 0.25 & - \\
\hline Gestational age, weeks. M (SD) & $29.6(2.4)$ & $39.9(0.9)$ & $<0.01$ & -10.8 to -9.6 \\
\hline Birth weight, grams. M (SD) & $1322(434)$ & $3497(495)$ & $<0.01$ & -2360 to -1990 \\
\hline Single births $\mathrm{n}(\%)$ & $68(68)$ & $48(96)$ & & \\
\hline Twin births $\mathrm{n}(\%)$ & $27(27)$ & $2(4)$ & & \\
\hline Triplet births n (\%) & $5(5)$ & 0 & - & - \\
\hline Parent characteristics & $\mathrm{n}=85$ & $n=49$ & & \\
\hline No. of children at home. Median (range)* & $2(1-7)$ & $2(0-5)$ & 0.67 & - \\
\hline Ethnicity (Caucasian) n (\%) & $77(77)$ & $45(90)$ & 0.30 & - \\
\hline Marital status (married) $\mathrm{n}(\%)$ & $89(89)$ & $47(94)$ & 0.27 & - \\
\hline Maternal education, years. M (SD) & $15.9(2.75)$ & $18.3(4.28)$ & $<0.01$ & \\
\hline Maternal age at delivery, years. Median (range) & $35(19-42)$ & $33(25-43)$ & 0.42 & - \\
\hline Trait anxiety. M (SD) & $35.9(9.28)$ & $34.2(8.35)$ & 0.26 & -1.3 to 4.8 \\
\hline Depression. Median (range) & $4.0(0-44)$ & $3.0(0-25)$ & 0.012 & - \\
\hline \multicolumn{5}{|l|}{ Ways of coping (relative scores). M (SD) } \\
\hline Confrontive & $0.119(0.080)$ & $0.119(0.085)$ & 0.97 & -0.029 to 0.028 \\
\hline Distancing & $0.110(0.078)$ & $0.108(0.077)$ & 0.85 & -0.024 to 0.029 \\
\hline Self-controlling & $0.143(0.075)$ & $0.144(0.079)$ & 0.94 & -0.027 to 0.025 \\
\hline Seeking social support & $0.170(0.075)$ & $0.165(0.089)$ & 0.73 & -0.023 to 0.032 \\
\hline Accepting responsibility & $0.091(0.087)$ & $0.062(0.084)$ & 0.059 & -0.001 to 0.058 \\
\hline Escape/Avoidance & $0.065(0.051)$ & $0.063(0.046)$ & 0.86 & -0.016 to 0.019 \\
\hline Planful problem solving & $0.188(0.094)$ & $0.240(0.125)$ & 0.005 & -0.088 to -0.016 \\
\hline Positive reappraisal & $0.114(0.070)$ & $0.098(0.069)$ & 0.19 & -0.008 to 0.040 \\
\hline \multicolumn{5}{|l|}{ Child characteristics } \\
\hline WISC-IV FSIQ†. M (SD) & $100.7(13.7)$ & $110.6(12.0)$ & $<0.001$ & -14.4 to -5.3 \\
\hline CBCL $\neq$ internalising (T score). M (SD) & $51.9(10.8)$ & $50.3(10.7)$ & 0.40 & -2.1 to 5.2 \\
\hline CBCL externalising (T score). M (SD) & $48.2(10.9)$ & $47.9(10.3)$ & 0.87 & -3.4 to 4.0 \\
\hline
\end{tabular}

*No. of children at home at assessment, excluding the index child.

tWechsler Intelligence Scale for Children fourth edition full-scale IQ.

‡Child Behavior Checklist. 
a stressful situation within the last week. Responses are made on a 4-point Likert scale, from $0=$ does not apply/not used to $3=$ used a great deal. The established procedure ${ }^{22}$ for converting raw scores to relative scores was used to control for the unequal number of items within the scales. This involved calculating the mean item score for each scale and dividing by the number of items in that scale, summing these averages, and dividing the average of each scale by the sum of the averages for all eight scales. $^{22}$ The WCQ has been widely used to explore parent coping. $^{23-25}$

Child Behavior Check List (CBCL), ${ }^{26}$ a widely used tool, ${ }^{27-29}$ measures parent perceptions of their child's problem behaviours. The CBCL consists of three categories of problems and a total score. The anxious/depressed, withdrawn/depressed and somatic complaints subscales are combined to produce the internalising problems scale (anxiety/depressive symptoms); aggressive behaviour and rule-breaking comprise the externalising problems scale (oppositional defiance and conduct); the remaining syndrome scales comprise social, attention and thought problems and do not have an overall scale score. Parents are asked to respond on a 3 -point Likert scale ranging from $0=$ not true to $2=$ very true or often true.

Beck Depression Inventory-second edition (BDI-II) ${ }^{30}$ is a 21-item measure of depressive symptomology. Items refer to loss of energy, changes to appetite, irritability, guilt and agitation. Parents were asked to respond on a 3-point scale ranging from 0 to 3 . Higher total scores on the BDI indicate greater symptom severity. Parents who score between 0 and 13 are classified as having minimal levels of depression, 14-19 mild depression, 20-28 moderate and 29-63 severe.

State Trait Anxiety Inventory (STAI), ${ }^{31}$ a 40 -item self-report tool, measures state and trait anxiety. We used the more stable trait anxiety in the current study which assesses the anxiety level of the parent as a personal characteristic. The 20 items of the trait anxiety scale include statements such as 'I worry too much over something that really doesn't matter', and 'I am content; I am a steady person'. Parents were asked to respond on a 4-point Likert scale from $1=$ almost never, to $4=$ almost always, with higher scores indicating greater anxiety.

Child IQ was assessed using the Wechsler Intelligence Scale for Children fourth edition (WISC-IV) ${ }^{32}$ which comprises four composite scales; verbal comprehension index (VCI), perceptual reasoning index (PRI), working memory index (WMI), processing speed index (PSI) and the full-scale IQ (FSIQ), with a mean of 100 and SD of 15 .

\section{Statistical analyses}

Demographic characteristics were compared across samples using the $\chi^{2}$ test for dichotomous data, and the independent $t$ test for continuous data. The Mann-Whitney $U$ test was used for BDI scores because of heteroscedasticity and non-normality of the data. Pearson's correlations were used to explore associations between measures of stress, anxiety and depression. Analysis of covariance (ANCOVA) examined the effects of group and gender on parenting stress controlling for years of maternal education. Finally, multiple linear regression was employed to investigate variables which would predict preterm parenting stress.

\section{RESULTS}

Characteristics of the 100 preterm and 50 full-term children and their parents are shown in table 1 . As expected, the groups differed in regard to gestational age $(p<0.01)$ and birth weight $(p<0.01)$ but not sex. At 7 years of age, the full-term children had significantly higher FSIQ scores than the preterm children ( $p<0.001)$, but did not differ on Internalising or Externalising behaviours. Parents of the full-term-born children had, on average, 2.4 more years of education than preterm parents $(p<0.01)$. Parents of full-term children used significantly more Planful problem solving coping compared with parents of preterm children; however, parents of preterms showed a trend towards higher coping through Accepting responsibility. Group differences were also apparent with regards to depressive symptomatology $(\mathrm{p}=0.012)$, with parents of the preterm group scoring higher than the full-terms. According to the BDI classification, two parents in the preterm group had severe depressive symptomatology, 3 had moderate and 10 were mild. One parent in the full-term group had a moderate level of depressive symptoms.

\section{Preliminary data reduction}

Pearson's correlations showed that the BDI measures of depression $(\mathrm{r}=0.515, \mathrm{p}<0.001)$ and anxiety $(\mathrm{r}=0.716, \mathrm{p}<0.001)$ were significantly associated with the PSI Parent stress domain; therefore, these were excluded from further analysis. The eight WCQ subscales showed only weak intercorrelations ranging from 0.059 to 0.394 , thus all were retained for further analysis.

\section{Group differences}

In the ANCOVA, years of maternal education was entered as a covariate and was not significantly associated with Parent stress $(p=0.161)$. There was a statistically significant difference on Parenting stress between the preterm and full-term groups ( $\mathrm{p}=0.027$; mean difference $=8.8,95 \%$ CI 0.885 to 16.670 ), but not in regard to sex $(\mathrm{p}=0.591$; mean difference $=2.8,95 \%$ CI -11.109 to 5.433). Parents of preterm children reported significantly more stress ( $M=115.6$, SD 27.2 ; $95 \%$ CI 111.1 to 121.4) than parents of full-term children $(M=106.8$, SD 20.8; 95\% CI 97.8 to 113.2 ). The mean difference between parents of preterm and full-term children was $\mathrm{M}=8.8$ (95\% CI 0.1 to 17.5). However, examination of the estimated marginal means showed that parents of preterm females expressed higher levels of stress $(M=120.6 ; 95 \%$ CI 113.4 to 127.8$)$ than parents of males $(M=111.9 ; 95 \%$ CI 104.7 to 119.1$)$. The mean difference between parents of preterm females and males was $\mathrm{M}=8.7$ (95\% CI -2.0 to 19.4$)$.

\section{Predictors of parenting stress in the preterm group}

Child behaviour problems (internalising and externalising), FSIQ, gender and the eight Ways of Coping (WCQ) subscales were entered into a multiple linear regression model to determine which variables were predictive of Parent stress. A statistically significant model emerged $(\mathrm{p}<0.001)$ which explained $30 \%$ (adjusted R square $=0.30$ ) of the variance in Parent stress (see table 2). Parent Escape-Avoidance coping, child sex and Externalising behaviour were significant predictors, with a positive relationship to Parent stress. IQ, Internalising behaviour and all other WCQ subscales were not significant predictors. Descriptive statistics showed that parents rated the externalising behaviours of their male children as higher $(M=50.7, S D 11.3)$ than those of female children $(M=45.8, S D 9.9)$, and mothers of girls $(\mathrm{M}=0.068, \mathrm{SD} 0.054)$ used more Escape-Avoidance than mothers of boys $(\mathrm{M}=0.062$, SD 0.049). Therefore, the interactions between gender and externalising behaviours, and between gender and Escape-Avoidance were added to the model. There was no significant interaction $(\mathrm{p}=0.403$ and $\mathrm{p}=0.307$, respectively). 
Table 2 Standardised and unstandardised regression coefficients for variables entered into the model

\begin{tabular}{|c|c|c|c|c|c|}
\hline Variable & B & SE & $\boldsymbol{\beta}$ & p Value & $95 \% \mathrm{Cl}$ \\
\hline WISC-IV FSIQ* & 0.197 & 0.174 & 0.101 & 0.261 & -0.149 to 0.542 \\
\hline Gender & 13.928 & 5.087 & 0.259 & 0.008 & 3.810 to 24.047 \\
\hline $\begin{array}{l}\text { WCQ† Confrontive } \\
\text { coping }\end{array}$ & 54.729 & 40.096 & 0.160 & 0.176 & -25.033 to 134.492 \\
\hline WCQ Distancing & 32.016 & 45.619 & 0.077 & 0.485 & -58.736 to 122.768 \\
\hline WCQ Self-controlling & 13.634 & 39.727 & 0.037 & 0.732 & -65.395 to 92.663 \\
\hline $\begin{array}{l}\text { WCQ Seeking social } \\
\text { support }\end{array}$ & 57.114 & 39.926 & 0.155 & 0.156 & -22.312 to 136.540 \\
\hline $\begin{array}{l}\text { WCQ Accepting } \\
\text { responsibility }\end{array}$ & 49.990 & 33.091 & 0.162 & 0.135 & -15.838 to 115.817 \\
\hline $\begin{array}{l}\text { WCQ Escape/ } \\
\text { Avoidance }\end{array}$ & 129.656 & 54.662 & 0.247 & 0.020 & 20.917 to 238.396 \\
\hline $\begin{array}{l}\text { WCQ Positive } \\
\text { reappraisal }\end{array}$ & 60.500 & 49.986 & 0.154 & 0.230 & -38.938 to 159.937 \\
\hline CBCL $\ddagger$ Internalising & 0.097 & 0.289 & 0.039 & 0.737 & -0.478 to 0.673 \\
\hline CBCL Externalising & 1.173 & 0.291 & 0.472 & $<0.001$ & 0.594 to 1.753 \\
\hline
\end{tabular}

\section{DISCUSSION}

In this prospective longitudinal cohort study, we found that parenting stress was significantly higher for parents of preterm children, compared with those born full-term, 7 years following birth. Previous studies have shown that parents of preterm children experience significant levels of stress in the first few years of life. ${ }^{134633}$ Our findings are consistent with the few studies which have explored parental stress in this group at school age. ${ }^{5}{ }^{6}$ It appears that parents of very preterm children continue to experience significant levels of stress which extends for many years beyond the birth of their child.

Importantly, we found that style of parent coping predicts stress in parents of preterm children at age 7 years. The positive relationship between Escape-Avoidance and stress suggests that parents who seek to ignore the problems associated with raising a preterm child will experience higher levels of stress. This is consistent with previous work showing that mothers of high-risk preterm children who use avoidance as a coping strategy have been shown to display higher levels of psychological distress. ${ }^{34}$ However, this is in contrast to the work of Singer and colleagues $^{6}$ who reported less maladaptive coping strategies in mothers of high-risk preterm children who experienced significant levels of strain. We found that parents of preterms showed more accepting responsibility coping and less planful problem solving coping compared with full-term parents, suggesting that coping is an important factor which impacts on the mental health of parents of children born preterm.

In this study of very preterm children free of major impairments, child cognitive ability was not related to parenting stress levels. Contrary to our early finding in this cohort that slower development from 8 to 18 months was associated with higher parenting stress, ${ }^{3}$ at age 7 years, child externalising behaviour (rather than IQ) was found to contribute substantially to parenting stress. There was a positive association between child externalising problems and parent stress suggesting that the preterm children's behaviours were a source of stress for parents. However, it is not possible to determine the directionality of this association; that is, if the child's behaviour was a source of stress for parents or a result of it. The child's sex was also an important predictor of parenting stress. Although parents reported more externalising problems in boys than girls, unexpectedly, it was the acting-out behaviour of girls which was associated with greater stress for parents. There is a major literature reporting that preterm birth is related to behavioural problems such as attention, and internalising (anxiety/depressive symptoms), ${ }^{793536}$ and to a lesser extent externalising (oppositional defiance and conduct) ${ }^{37} 38$ behaviours. Some studies have reported sex differences in behaviours among very preterm children, with boys presenting with more externalising, and girls more internalising problems. ${ }^{9}$ Our findings suggest that parents of preterm girls experience more stress associated with their externalising behaviour problems than parents of preterm boys at school age. Cultural stereotypes which allow boys, but not girls, to act aggressively may mean that parents are interpreting the girls' behaviour as more problematic, resulting in higher levels of stress. Parents may have cause for concern as girls who display aggressive behaviours have been shown to be at higher risk for loneliness compared with males. ${ }^{39}$

\section{LIMITATIONS}

Given the mediating effects of social support on stress, ${ }^{2}$ the addition of a measure of support would have added to the robustness of our findings. However, maternal social support has been found to be related to fewer internalising but not externalising behaviours at age 3 years, ${ }^{11}$ and there appears to be no difference between amount of social support received by preterm and term-born families at 7 years..$^{5}$ Our analysis did not take into consideration the lack of independence between multiple births, and we did not control for those parents with twins and triplets. As this was an observational study, we are unable to determine the causal nature of the relationship between stress and coping, and stress and externalising behaviour. It is equally possible that Escape/Avoidance coping causes stress, and that stress is caused by Escape/Avoidance. The self-report nature of the selected measures may also have introduced a degree of bias into our findings.

\section{CONCLUSIONS}

The present study found that parents of very preterm children continue to experience stress well beyond the first few years of life. Efforts should be made to focus on the development of more adaptive parent-coping mechanisms, and behavioural interventions for preterm children who exhibit externalising behaviours, to reduce levels of stress. Moreover, parents of preterm girls experienced higher levels of stress than those of boys, suggesting that the gender identities which parents assign to their children may be restricting in very preterm children. The behavioural problems associated with preterm birth continue to manifest with age, which implies that stress levels of parents may not decrease for some time. With support, parents could be helped to accommodate to the behaviour of their children, which may aid in reducing levels of stress.

Acknowledgements We wish to thank the parents and children who participated in this study, and the staff of the Early Experience Unit in the Developmental Neurosciences and Child Health cluster of the Child and Family Research Institute, and the Neonatal Follow-up Program at the British Columbia's Women's Hospital and Health Centre.

Contributors MAL and REG drafted the manuscript and conducted analysis of the data. REG conceptualised and designed the study and approved the final draft of the manuscript with ILC, AS and MAL.

Funding This research was supported by grants to REG from the National Institute for Child Health and Human Development (HD39783), Canadian Institutes for 
Health Research grant (MOP42469), Human Early Learning Partnership (HELP) and Michael Smith Foundation for Health Research.

Competing interests None.

Patient consent Obtained.

Ethics approval Granted by The University of British Columbia/Children's and Women's Health Centre of British Columbia Research Ethics Board.

Provenance and peer review Not commissioned; externally peer reviewed.

\section{REFERENCES}

1 Gray PH, Edwards DM, O'Callaghan MJ, et al. Parenting stress in mothers of very preterm infants -influence of development, temperament and maternal depression. Early Hum Dev 2013;89:625-9.

2 Pinelli J. Effects of family coping and resources on family adjustment and parental stress in the acute phase of the NICU experience. Neonatal Netw 2000;19:27-37.

3 Brummelte S, Grunau RE, Synnes AR, et al. Declining cognitive development from 8 to 18 months in preterm children predicts persisting higher parenting stress. Early Hum Dev 2011;87:273-80.

4 Singer L, Salvator A, Guo S, et al. Maternal psychological distress and parenting stress after the birth of a very low-birth-weight infant. JAMA 1999;281:799-805.

5 Treyvaud K, Lee KJ, Doyle LW, et al. Very preterm birth influences parental mental health and family outcomes seven years after birth. J Pediatr 2014;164:515-21.

6 Singer LT, Fulton S, Kirchner HL, et al. Parenting very low birth weight children at school age: maternal stress and coping. J Pediatr 2007;151:463-9.

7 Treyvaud K, Anderson VA, Lee KJ, et al. Parental mental health and early social-emotional development of children born very preterm. J Pediatr Psychol 2010;35:768-77.

8 Gray RF, Indurkhya A, McCormick MC. Prevalence, stability, and predictors of clinically significant behavior problems in low birth weight children at 3, 5, and 8 years of age. Pediatrics 2004;114:736-43.

9 Reijneveld SA, de Kleine MJK, van Baar AL, et al. Behavioural and emotional problems in very preterm and very low birthweight infants at age 5 years. Arch Dis Child Fetal Neonatal Ed 2006;91:F423-8

10 Essex MJ, Klein MH, Cho $\mathrm{E}_{\text {, et }}$ al. Maternal stress beginning in infancy may sensitize children to later stress exposure: effects on cortisol and behavior. Biol Psychiatry 2002:52:776-84.

11 Miceli PJ, Goeke-Morey MC, Whitman TL, et al. Brief report: birth status, medical complications, and social environment: individual differences in development of preterm, very low birth weight infants. J Pediatr Psychol 2000;25:353-8.

12 Crnic KA, Greenberg MT, Ragozin AS, et al. Effects of stress and social support on mothers and premature and full-term infants. Child Dev 1983;54:209-17.

13 Muller-Nix C, Forcada-Guex M, Pierrehumbert B, et al. Prematurity, maternal stress and mother-child interactions. Early Hum Dev 2004;79:145-58.

14 Singer $\mathrm{LT}$, Fulton $\mathrm{S}$, Kirchner $\mathrm{HL}$, et al. Longitudinal predictors of maternal stress and coping after very low-birth-weight birth. Arch Pediatr Adolesc Med 2010;164:518-24

15 Saigal S, Pinelli J, Streiner DL, et al. Impact of extreme prematurity on family functioning and maternal health 20 years later. Pediatrics 2010;126:e81-8.

16 Grunau RE, Holsti L, Haley DW, et al. Neonatal procedural pain exposure predicts lower cortisol and behavioral reactivity in preterm infants in the NICU. Pain 2005; 113:293-300

17 Grunau RE, Haley DW, Whitfield MF, et al. Altered basal cortisol levels at 3, 6, 8 and 18 months in infants born at extremely low gestational age. $J$ Pediatr 2007:150:151-6.
18 Grunau RE, Whitfield MF, Petrie-Thomas J, et al. Neonatal pain, parenting stress and interaction, in relation to cognitive and motor development at 8 and 18 months in preterm infants. Pain 2009;143:138-46.

19 Böhm B, Katz-Salamon M, Smedler A-C, et al. Developmental risks and protective factors for influencing cognitive outcome at $5 \frac{1}{2}$ years of age in very-low-birthweight children. Dev 2002:44:508-16.

20 Abidin R. Parenting stress index: professional manual. 3rd edn. Lutz, FL: Psychological Assessment Resources, Inc., 1995.

21 Folkman S, Lazarus RS. Manual for the ways of coping questionnaire. Palo Alto, CA: Consulting Psychologists Press, 1988

22 Vitaliano PP, Maiuro RD, Russo J, et al. Raw versus relative scores in the assessment of coping strategies. J Behav Med 1987;10:1-18.

23 Lambert VA, Lambert CE, Ito M. Workplace stressors, ways of coping and demographic characteristics as predictors of physical and mental health of Japanese hospital nurses. Int J Nurs Stud 2004:41:85-97.

24 Ahlström G, Wenneberg S. Coping with illness-related problems in persons with progressive muscular diseases: the Swedish version of the Ways of Coping Questionnaire. Scand J Caring Sci 2002;16:368-75.

25 Pisula E, Kossakowska Z. Sense of coherence and coping with stress among mothers and fathers of children with autism. J Autism Dev Disord 2010;40:1485-94.

26 Achenbach T, Rescorla L. Manual for the ASEBA preschool forms and profiles. Burlington, VT: University of Vermont, Research Center for Children, Youth, and Families, 2000.

27 Diler RS, Birmaher B, Axelson D, et al. The Child Behavior Checklist (CBCL) and the CBCL-bipolar phenotype are not useful in diagnosing pediatric bipolar disorder. J Child Adolesc Psychopharmacol 2009;19:23-30.

28 Stoelhorst GMSJ, Martens SE, Rijken M, et al. Behaviour at 2 years of age in very preterm infants (gestational age $<32$ weeks). Acta Paediatr 2003;92:595-601.

29 Ho J, Epps A, Parry L, et al. Rehabilitation of everyday memory deficits in paediatric brain injury: self-instruction and diary training. Neuropsychol Rehabil 2011;21:183-207.

30 Beck AT, Steer RA, Ball R, et al. Comparison of Beck depression inventories -IA and -II in psychiatric outpatients. J Pers Assess 1996;67:588-97.

31 Spielberger CD, Gorsuch RL, Lushene R, et al. Manual for the State-Trait Anxiety Inventory. Palo Alto, CA: Consulting Psychologists Press, 1983.

32 Wechsler D, Kaplan E, Fein D, et al. Wechsler Intelligence scale for children fourth edition-integrated. San Antonio, TX: Harcourt Assessment, Inc., 2004.

33 Kaaresen PI, Rønning JA, Ulvund SE, et al. A randomized, controlled trial of the effectiveness of an early-intervention program in reducing parenting stress after preterm birth. Pediatrics 2006;118:e9-19.

34 Eisengart SP, Singer LT, Fulton S, et al. coping and psychological distress in mothers of very low birth weight young children. Parent Sci Pract 2003;3:49-72.

35 Vinall J, Miller SP, Synnes AR, et al. Parent behaviors moderate the relationship between neonatal pain and internalizing behaviors at 18 months corrected age in children born very prematurely. Pain 2013;154:1831-9.

36 Brummelte $S$, Grunau RE, Zaidman-Zait A, et al. Cortisol levels in relation to maternal interaction and child internalizing behavior in preterm and full-term children at 18 months corrected age. Dev Psychobiol 2011;53:184-95.

37 Huhtala M, Korja R, Lehtonen L, et al. Parental psychological well-being and behavioral outcome of very low birth weight infants at 3 years. Pediatrics 2012;129: e937-44.

38 Georgsdottir I, Haraldsson A, Dagbjartsson A. Behavior and well-being of extremely low birth weight teenagers in Iceland. Early Hum Dev 2013;89:999-1003

39 Coplan RJ, Closson LM, Arbeau KA. Gender differences in the behavioral associates of loneliness and social dissatisfaction in kindergarten. J Child Psychol Psychiatry 2007:48:988-95. 